\title{
Meet me at the Coconut Gate at 8.30: 'Mikmak' as a Site of Socialisation
}

\author{
David Levin ${ }^{1}$ \\ Sharon Ramer Biel \\ The School of Media Studies, College of Management Academic Studies, Israel
}

\section{doi:10.5937/comman1329125L}

Summary: Discussion of trans-media platforms over the last two decades has focused, among other things, on the social significance of such media products. Researchers have asked to what extent they promote democratic values, freedom of action and creativity and hence what is their contribution to the socialisation of children. This study seeks to engage with this discussion by investigating the impact of 'Mikmak,' a trans-media project directed at children which includes an internet site, computer game, feature film and television series. The study, which is rooted in part on culture studies, combines a semiotic analysis of 'Mikmak' content and ethnographic study of participants in it.

Content analysis reveals a strong connection between the platform's content and an individualist orientation in Israeli society over the last two decades, although this is only partially true of the way children in the 7-11 year age group play the game. This age group clearly prefers the computer game, and while playing together they actually counter the individualist ideas promoted by the 'Mikmak' platform. This may be explained by the fact that collectivist values are still important in Israeli society, as reflected in traditional children's games. We conclude, therefore, that individualist content and a creative undermining of it are both rooted in Israeli cultural narratives, and that the potential contribution of media content to socialisation of children is contingent on its reception by them.

Keywords: childhood, trans-media, children's games, cultural values, cultural studies, Disneyization, interpretive communities, socialization

\footnotetext{
${ }^{1}$ ddnsle@gmail.com
} 


\section{About 'Mikmak'}

The 'Mikmak' platform is hugely popular. The website and its companion television series, offline play venue, feature film, book, smartphone application and blog combining all five, was ranked sixth in a Google survey of similar platforms, with a leap in hits during 2011 (Shemer, 2011). According to the site's own data, children spend an average of one hour on it each day, and to date have created 4,000,000 'Mikmak' characters.

A child logging on to the site is assigned a naked, child-like virtual character which they can design as they please, clothing it and imparting an identity to it expressed in colour, gender and a first name unique to that character. The game is divided into zones and 'gates,' (the coconut gate mentioned in the title, for example) displayed on a map. Players can move characters between zones and through the gates. These spaces are in part public, such as a café, cinema or town square, thereby enabling the characters to engage in meetings and verbal interactions - sometimes prearranged - with characters who might be new friends or friends from school. In addition, these virtual public spaces hold the promise of meeting characters from the corresponding television series and the offline play venue. There are also private spaces such as the character's bedroom, and other zones such as The Island, the Space Centre and The Jungle, where characters can play or take on challenges. A major aim of the game for all characters in all zones is to win 'Mikmak money' which is then 'spent' on designing and grooming the character. The 'Mikmak' website can be visited for free, but many activities on it are restricted to subscribers only, at a cost of approximately $7 \$$ per month.

The offline venue is also divided into zones: a game zone and shopping area are located outside and may be visited free of charge. There is a 'Mikafé' simulating the café on the website, selling children and parents sweets and beverages bearing the site's name, like 'Mikice-cream' and an offline shop, which sells only branded merchandise also available on the website. The entire space is decorated in colours and props as they appear on the 'Mikmak' website. The companion television series has been running for three seasons, of 26 episodes each. The series features four main characters personifying four prominent prototypes of youth culture: Max (the cool boy), Zoe (the cool girl), Sunny (the genius) and Jimbo (the musician). There is also a long list of supporting characters also featured on the website and at the play venue (the Mayor and 
Mrs Mikiavelli, to mention just two). 'Sarit's' Blog (substituted last year by 'Inbal's' blog) is a common thread running through all parts of the platform. This blog is supposedly run by a female character presenting herself in a picture as a young girl. She is responsible for making announcements concerning activities taking place at different parts of the platform as well as moderating children's comments and feedback.

We will examine the platform from a cultural angle and therefore begin by bringing together theoretical discussion of trans-media platforms, a cultural studies and research into children's games in Israeli society.

\section{Trans-media and cultural studies}

The term 'trans-media' refers to a media product incorporating common, 'trans-medial' elements (Ryan, 2008) which are coordinated across different formats including television, cinema and internet applications. The full meaning of the content can only be ascertained when all the formats are accessed together, although each element stands alone and can be taken up separately. Discussion of the social significance of this cultural product addresses, among other things, the freedom of operation which the gaps between its textual elements generate for its users. Those arguing in favour of this type of product mention its all-inclusive but disrupted structure. They propose an interpretative framework similar to that employed by television researchers who argue that the disrupted television text promotes interpretative flexibility (Fiske, 1996). Prominent among these is Henry Jenkins (2006), who claims that there has been a shift in the relations between technology, markets, genres and audiences. Jenkins and his supporters believe that disruption obliges the audience to become active participants in the cultural process: distinguishing between elements, searching out new information and at times creating their own content. The text situates the audience as "nomadic, disloyal, socially connected, defiant, loud and public" (Jenkins, 2006: 34), insisting on their right to self-expression (Canclini, 2001). Similarly, it has been argued that the dissemination of consumer messages by various means involving a need to search and converse, educates consumers in a new kind of political engagement (Apperley, 2007). When the target audience of a trans-media product is children, they can acquire values independently of adult interference (Lee, 2001). They can "[play] with power" (Kinder, 1991), acquiring the confidence to remove obstacles or to buy 
what they need (Alper and Herr-Stephenson, 2013). At any rate, devotees of the 'Mikmak' package argue that children can prepare for socialisation into a new culture of interactive media.

Detractors from trans-media packages direct attention to the messages they send, stressing that that they provide a kind of safety net allowing users to minimise risk in their encounter with new, unfamiliar content (Aarseth, 1997; Hutcheon, 2006). These opponents of trans-media platforms believe that the consumer super-structure situates users, not as active citizens but rather as consumers whose participation is the antithesis of dynamism and creativity (Marshall, 2004). For these two reasons such platforms tend to constitute a closed text (Eco, 1989) which directs the reader to a limited range of meanings - to which in the case of 'Mikmak' all the elements of the platform conform. "Disneyization" (Bryman, 1999) is one such model exemplifying a 'closed' narrative. According to Bryman, the same principles guiding Walt Disney's theme parks 'dominate more and more sectors of American society as well as the rest of the world' (Bryman, 1999: 26). Bryman and other researchers following him, claim that components of a Disney-type model can also be found in restaurants (Beardsworth and Bryman, 1999), airports (Hamilton and Harlow, 1995) and even on digital platforms (Op'tLand, 2009). Bryman (1999) himself identifies four trends. The first is theming, meaning or branding that sets a venue apart from other places. The second trend, merchandising, involves the branding of objects sold at the venue as authentic and otherwise difficult to obtain. The third, de-differentiation, means the interlocking of shopping and recreation, while the last, 'emotional labour,' pertains to the warmth lavished by workers on the venue's guests. Although Bryman stresses that his approach is organisational, we seek to explore the relevance of Bryman's Disneyization model, to our cultural approach. We use this model to interpret the general structure of plot and setting (marketing and branding) and the positioning of the implied reader and author ${ }^{2}$ (de-differentiation and emotional work).

Both advocates for and opponents of trans-media platforms rely on structural textual analysis. Michael Newman (2012) has, however, argued that such analysis usually derives from literary criticism rather than culture research, and misses a world of meanings emerging from the social and historical context in

\footnotetext{
2 The term 'implied author' is Wayne Booth's (Booth, 1983). The 'implied reader' is the hypothetical figure for whom the work is intended (Iser, 1972).
} 
which particular content is created or consumed. Moreover, this kind of structural analysis relies on the way in which a text situates its hypothetical, rather than real audiences, making assessments which may have nothing to do with the text's actual consumption. Stanley Fish (1980) and Janis Radway (1984) sharpen this distinction, referring to interpreting communities: a collection of people gathered together (whether consciously or unconsciously) who share media text preferences and whose particular interpretations of the text are contingent on time and place. Such an audience might read a text differently from the way its writer or critics suppose. Their interpretation is not personal but is rather the 'property' of a community saturated in ideology and ways of imposing a particular reception on its members (Fish, 1980; Radway, 1984).

The above discussion is particularly relevant to the socialisation of children. Throughout history, especially during the last century, there has been disagreement as to whether communication technologies contribute to the socialisation of children into the adult world. Thus, scholars of technological determinism have argued that since television broadcasts signs which require no mediation to be understood, it undermines parents' authority (Postman, 1983). Scholars of trans-media platforms, on the other hand, argue that their use promotes learning processes because of their inbuilt demand for 'activity' (Kinder, 1991; Seiter, 1993; Alper and Herr-Stephenson, 2013). In this study, the above arguments are considered in a cultural context, with regards to both content and audience.

\section{Israeli society, childhood and children's games}

Jewish Israeli over the last forty years society has become torn between individualist and collectivist values (Katz and Hass, 2000). Collectivism, expressing itself as a strong sense of togetherness and social solidarity, has always been important throughout the history of the Jewish people, and particularly in Israeli society since Jews first began to resettle Palestine in the late $19^{\text {th }}$ century. It is preserved and strengthened by the constant security threat facing the country (Mayseless and Salomon, 2004). This climate of solidarity persists despite an increasing tendency towards individualism, materialism and Western, especially American, culture, observed in Israel over the last twenty years (Almog, 2004; First and Avraham, 2009). The ideological, complex and schizoid nature of Jewish Israeli society reaches children and young people via socialisation processes 
and is expressed in the messages delivered to them by many socialising agents including family, schools and youth movements.

In the early years of Israel's existence, childhood was seen as part of the collectivist atmosphere, a preparatory stage on the way to conscription into compulsory army service and later to other national goals. To this day, children often remain in the same class group throughout their school years, unlike the situation in the US (Katriel, 1999). Activities promoting solidarity among the students in the class are prioritized, while nationalist oriented youth movements are still important in Israel, with around 35\% of Jewish Israeli children and youth participating in them (Weisblei, 2011).

In recent years, alongside the rise of individualism and widespread Americanisation, a change in views on childhood has been projected onto Israeli children's leisure activities. In the past, society was seen as largely responsible for children's development and wellbeing, where today it is their parents who are considered primarily responsible for them (Almog, 2004). Parents have come to understand that not doing the right thing regarding their children's development is liable to have far reaching consequences and have begun to take more care to nurture their children as individuals. Thus they seek to supervise their children's leisure more closely, while commercialised leisure activities flourish: clubs and leisure activities aimed at nurturing individual talents, as well as media platforms like 'Mikmak' which label themselves as educational.

This state of affairs contradicts what is known in Israeli social science about children's games which have always been seen as the province of adult values, with children adding meanings in order to meet their own needs in any given time or place (King, 1992). Tamar Katriel (1999) puts this universally relevant truism in a cultural context, linking the collective orientation of Israeli society to the social nature of two major childhood occupations: 'swaps' and 'treating.' These two games take place at times and in places not necessarily supervised by parents, but evidently abide by rules of the culture in which the children are growing up.

'Swaps' involves an exchange of game cards or other collectibles. Despite necessitating interpersonal interaction, in the Israeli context a verbal community has grown up around 'swaps' which typically involves a mutuality between children premised on long term expectations for returns on investment of time, effort or money to acquire the collected items. The exchange takes place in public with children not directly involved acting as partners or advisors. 
'Swaps' corresponds with rituals of 'treating' where a child gives some of his food or snack to other children around him at that moment, not just his own close friends. Katriel (1999) makes it clear that this is not about eating, but rather constitutes a symbolic act aimed at authorising limits of the group of chums to which the treating child belongs. Katriel (1999) sees this game as experimenting with a generalised exchange mechanism in which future payback is promised and there is every expectation that it will in fact come. Despite the difference between the two games, Katriel (1999) concludes that in both, children teach themselves to manage the conflict between personal desire and the demands of society, seeing themselves as part of a larger social world. Both games fit the prevailing collective orientation of Israeli society which still manages to persist in an age of rising individualism.

Rather than these traditional children's games, however, examination of current data on children's leisure culture in Israel reveals that playing on computer platforms $(33 \%)$ and meeting friends $(25 \%)$ constitute the major leisure activities engaged in after school hours (Ynet, 2013). The present study therefore brings together these two preferred leisure activities and examines the relations between them, against a background of the conflicting value orientations prevalent in Israeli society today.

\section{Methodology}

We use a cultural studies approach to examine the 'Mikmak' platform as used by Israeli children, applying a combination of semiotic structural analysis situating elements of the platform in a broader cultural context and analysis of 'Mikmak's' reception by its interpretative community. We have chosen Bryman's Disneyization model as an organising principle in our semiotic analysis. As we point out above, despite its organisational orientation, this model can help us to discern a narrative and an implied author and reader in trans-media platforms. In order to examine the platforms' reception we have chosen an ethnographic approach which combines observation and interviews.

We examined an interpretative community of ten children aged 7-11 years, who all know each other, live in the same neighbourhood and go to the same school. This is a large suburb by Israeli standards (population around 15,000), housing a middle class population. The children live up to $2 \mathrm{~km}$ apart so that visits depend on rides with parents. The children are in school until the early 
afternoon, followed in some cases by an afterschool programme run by the school, arriving home in the late afternoon with homework and clubs still to come. We became acquainted with the game and its importance through our own three daughters aged 10 (D.L.), 10 and 11 (S.R.-B.) who go to the same neighbourhood school as the interviewed subjects. We talked to them individually and then got them together to play 'Mikmak' and observed their interaction. We also watched the 'Mikmak' television series with them and took them to the play venue. Armed with this initial but quite extensive knowledge, we invited other children to participate in 15 minute interviews and to allow unobtrusive observation while they played on 'Mikmak' for about an hour and a half. We again consulted our daughters during the writing and conclusion phase of the study in order to ascertain the reception of our conclusions from a child's point of view.

Observation of children one knows, especially family members, in a study of this kind (e.g. Kinder, 1991) risks a loss of objectivity (problematic in any qualitative study) but holds many advantages. As Shaw, Brady and Davy (2011) have argued, children can participate actively in research as guides. Our involvement of our children facilitated a natural presence in the research field. Our daughters provided information which helped us manage the platform as well as helping to interpret the behaviour of its audience, besides helping to enlist other children in the study. They taught us 'Mikmak' language ('specials,' 'achievements,' 'Mikmak day') and about the significance of the platform for children. Their viewpoint also helped us to see the way children confer meaning on their play habits from their 'native' (Geertz, 1976) rather than from an adult point of view.

\section{Findings}

Investigation of the 'Mikmak' platform using a Disneyization model reveals a successful attempt to create a 'closed text' and to direct it at a target audience of children as individual consumers.

\section{Theme and marketing}

Walt Disney's massive success stems in part from the company's concept of visual unification in different spaces: Adventureland, the Wild West and other 
movie sets, thereby lending uniform meaning to a variety of activities, and at the same time setting Disney theme parks apart from other play arenas.

Like Disney, the 'Mikmak' computer game, television series, play venue and feature film create a space which while in some senses devoid of cultural ambience actually constitutes a pastiche of Walt Disney's America. It is also organised by zones sharing a common visual feature. The website, for instance, features a jungle, deep sea and urban zones housing the 'Mikmak Town Hall' and virtual 'Mikafe.' The television series is an extension of this urban zone, while the offline play arena features a collection of representations from both these symbolic spaces.

The trans-medial elements of the 'Mikmak' platform create an appearance suited to cultural globalisation apparent already on its title page with its image of leafy trees against a plain blue background (http://www.mikmak.co.il). For Israelis, this is an image evocative of remote, exotic islands, untouched by civilisation. On the face of it, this might be seen as a signifier of romantic pluralism (Wheeler, 1962) but all the zones display American cultural icons aligning the platform with an American oriented, Western hegemony. Thus the 'Mikafe' resembles an American diner and the platform's urban landscapes are reminiscent of Walt Disney's Main Street USA. Even the lead characters on the television series, whose names are not necessarily American, are all white and wear jeans and baseball caps, have long, tousled hair and are interested in science and rock music.

On a narrative level too, 'Mikmak' includes Western themes familiar to Israeli children. The Mayor of Mikmak (an older man sporting a large moustache, reminding one of the children interviewed of an American sheriff) was elected following a tough race against the local clothing store owner (a strong woman fashioned after the generic soap opera baddy). The plot driving the series involves repeated attempts by this female candidate to overthrow the Mayor, after her defeat in democratically held elections (with the participation of the website's users). She is trying to take over Mikmak City so that she can destroy the laboratory built by the lead characters and replace it with a shopping mall.

The story is told by the television series, but the game platform calls upon children to play with the characters or to save 'Mikmak City' by voting in the mayoral elections. Bryman's second principle is that an entire construct is 
marketed including common branding of the setting and of the story. Mutual merchandising of the 'Mikmak' platform goes on all the time; the television characters are on the site and some tasks involve them. The children buy tickets for the play venue on the site and use toy money they receive there to buy products online from the site when they return home. The feature film and a book, developed later, are prominently advertised on the 'Mikmak' website.

The unified branding of the site and mutual marketing of some items are trans-medial (Ryan, 2008). Authors collaborate to create a visually unified world and a unified narrative which like other culture products, have had all localising elements removed in a process of 'deodorizing' (Iwabuchi, 2002). This is a world far removed from the children's everyday lives. Although the computer game includes activities tailored to Jewish holidays and the user language on all elements of the platform is Hebrew thus linking it with a banal nationalism (Billig, 1995), the rest of the platform is not at all local. The foreignness is narrative as well: all four protagonists of the television series and the children replaying their actions on the game are called to stand by the local flag in order to save their city, but only briefly, while Israeli children learn of the importance of the collective (whether national or local) which one must always stand by.

\section{De-differentiation}

'The de-differentiation of spheres' is a state of affairs whereby activities associated with different spheres of life become intertwined (Bryman, 1999). In Walt Disney we see the de-differentiation of enjoying theme park rides on one hand and shopping on the other. Thus for example, food is sold in stylised food venues such as 'Main Street USA,' as part of the general backdrop. Critics of 'Mikmak' (Marshall, 2004) note that activities conforming to the de-differentiation principle shape the children as individualists; sellers and consumers rather than citizens intrigued by the possibility of contact and interaction with others (Alper and Herr-Stephenson, 2013). This is consistent with the process of individualisation undergone by Jewish Israeli society over the last two decades.

A page on the 'Mikmak' website aimed at parents, declares that the creators' aim is not only profit but also to enable children 'to be creative and to play wonderful games.' This statement notwithstanding, in practice almost all participation in the game involves using 'Mikmak money.' Most of the stations in the offline play venue also involve winning 'Mikmak money' which is put 
in the children's virtual 'account' with a 'credit card' they are given at the box office. We noticed that those stations not rewarding the children with money were deserted.

This consumer activity is augmented on special 'Mikmak days' declared by the website on which children can buy 'special,' limited edition items sold only on those days, or take part in competitions in which the children can win not only money but also 'achievements' with the winner's name appearing on the website.

\section{Emotional work}

A friendly demeanour and warm welcome extended to visitors are key elements in generating positive feeling among visitors to Walt Disney theme parks. Staff members are instructed to give the impression that they enjoy their job not seeing it as work at all. The 'Mikmak' platform adopts this approach, but unlike the joint address to parents and children in Disney parks we discern two separate 'target audiences' for 'Mikmak' each requiring a different approach. While the children enjoy to a sensitive, warm and personal form of address, attentive to their voice and allowing them room for self-expression, the explicit and implicit address to parents presents the 'We' of the platforms creators as keen to promote both their children's development and safety.

The attempt made to generate a warm, inclusive atmosphere between game moderators and children is manifested in both the virtual section of the platform and beyond it, first by attempts to bridge the age gap between the two. Thus for example, staff at the play venue are young, often joining in with groups of playing children. Online users' communication is moderated by 'Sarit' (later replaced by 'Inbal'), who is pictured as a long-haired Mikmak girl with a smiling, child-like face. 'Sarit' uses her blog to publish notices and to disseminate marketing information. 'Sarit' addressed the children ahead of a new book release and its distribution to stores in February 2013, noting that she was deeply impressed by 'their amazing feedback' adding, 'remember how we promised to reward those who guess right?' She then interrupted her writing to say, 'We have winners of the new Mikmak book!' and announced the winners' names. It seems that 'Sarit's' statements stirred up great excitement among many children logged on to the site. Children who had not yet to learned to write contributed a keyboard letter sequence to express their excitement, while 
those who could write shared statements such as 'a dream come true... but I wish everyone could have Sarit, Sarit is fun.'

The creators of the site represent themselves to parents as willing to contribute to their children's education. In a letter to parents, the site's owners point to the wealth of educational activities available on it, reassuring parents that 'the activities are designed especially for children in both content and presentation' and that 'some of the content has been checked by a team of reviewers.' Alongside this educational statement, the site's creators' implicit message to parents is their promotion of human "orders of discourse" (Foucault, 1971). So, for example, the smiling 'Sarit' is replaced by a non-human, sophisticated filter designed to block inappropriate words and phrases and prevent exchanges of phone numbers or email addresses among children. Moreover, the page informs parents that they can decide with which 'Mikmak' characters their children can interact freely or whether interaction is to be restricted to a fixed list of acceptable words. This faceless mechanism allows no arguments or negotiations, declaring it to be in its power to remove from the site any child disobeying the rules, automatically. Similar 'hands off' policing greets the children on arrival at the offline game venue. The game zone can only be entered with a pre-booked, online ticket bearing a specific date and time and guests may spend a maximum of two hours at the venue. When the two hours are up, the child can no longer activate her ticket.

The two implied authors of the platform, Sarit/Inbal and the enforcers of the rules go further in characterising the player as an individual, in this case not as a consumer subject but as a commercial object. The blog moderators as implied authors attempt to build a 'brand community' (Muniz and O'Guinn, 2001) around themselves while the language moderators flatten out the potential connection between children, emptying their communications almost entirely of the ability to open up or talk freely (Apperley, 2007). Giving adults control is consistent with ideas current in Israel about parental responsibility for the development and wellbeing of their children (Almog, 2004). This not only complements the platform's projection of a visual and narrative 'closed text' but also suits the individualistic and consumer orientation prevalent in Israeli society. 


\section{The game: putting friends first}

If we shift our attention from the platform's text to the way the children play on it we discover a more complex picture. On one hand, it is quite clear that the visually and narratively closed content impacts its reception. The subtle differences between the 'Mikmak' game and the offline play venue are negligible as far as the children are concerned. They relate in the same way to a character encountered in one medium as another. Thus, for example, one child said he'd been sent off the site because he swore at the wicked Mrs Mikiavelli when she appeared on the site. Another told us that when she visits the play venue she feels as though she's entering a computer game.

The essential difference between the meanings embedded in the platform and the way it is received by its audience lies, we believe, in the positioning of the children. While the platform situates them as individuals - a consumer subject or an object of supervision - the players see themselves first and foremost as members of their everyday social circle. This is expressed in their absolute preference for the computer game over the movie, the book or television series and in the way they join the game and the contexts in which it is played.

\section{Ways to join in the game}

All the children found out about the platform from other children and use it knowing that other friends use it too. Absence of friends to play or chat with would be a reason to stop playing on the platform. This is known to be the case with other digital children's games too (Yee, 2006) but as we shall see, in the case of 'Mikmak' there are also environmental and cultural factors involved. Some children told us that they learned about 'Mikmak' from conversations with classmates in the school yard so that there were entire classes in which all the children played on 'Mikmak' and others which did not. Other children found out about the platform in their afterschool programmes or from family members or friends who came to visit. One interviewee stressed the social impact of the game:

I was in second grade in my afterschool programme where I'd made a lot of friends and I realised they all play just one thing, 'Mikmak'. . . when I came I saw them all [playing] so I asked what it's like... Ron, he's a buddy of mine that I met in the afterschool programme... so he helped me get a lot of 'achieve- 
ments' friends help each other but Ron got 'achievements' for me and for Ido and for lots of others. $\left(\mathrm{Ofer}^{3}\right)$

The girls reported similar experiences. Shelly for example said

It all began in third grade... we became best friends... we have lots in common we both adore 'Mikmak'... she gave me a great wallpaper that someone had lost for me and gave me clothes and also won 300 Mikmak money for me.

Children who found out about the game from their peers in turn showed others, such as their younger siblings, how to play and shared a 'Mikmak' game with them. The game spreads through the neighbourhood as children search for ways to expand the circle of participants. This drive led four girls to collect money to buy membership for a friend whose parents would not allow her to buy it for herself, as a birthday present, so that she could continue to participate in what had become the focus of their social lives.

\section{The offline game}

The children's participation in 'Mikmak' platform activities whether it be the computer game or less often watching the television series, forms the basis of visits to each other's homes. Such a meeting would be organised by one child suggesting to another that they 'come over to find out what's new on the game' or to help each other 'earn specials'. This might in fact be an expression of friendship but it also expresses a desire to demonstrate power (one girl said she asked her parents to forbid her to use the computer when a certain friend came over who used to tease her about how slow her fingers were on the computer game). It might even contribute to a courtship: boys suggested coming over to girls' homes to 'help them' with 'Mikmak'. One girl said she let one of the boys beat her in a competition because I know boys like to win (Shir). Successful meetings involved a shared game in which children set their 'Mikmaks' side by side and competed or traded with each other. While playing or while taking a break, the children enjoyed talking about the characters, or planning visits to the play venue (they all reported preferring to go there together with friends) or gossiping. Activity directly concerning the game itself or other, behind

\footnotetext{
${ }^{3}$ Not his real name. All the children's names have been changed to preserve their anonymity.
} 
the scenes activities tangentially connected with it, therefore involves phatic strengthening of social bonds and reinforces the participants' social values (Malinowski, 1923). One interviewee told us of information he sent to his friends about problems on the site which if spotted, would confer upon them a lot of 'Mikmak' money. Others described conversations about the site's operators, such as wondering if 'Sarit' actually existed or if she was in fact the mother of a 'child surfing' or the twelve year old girl shown in her picture. 'Sarit's' replacement by 'Inbal' led to unfavourable comparisons in which 'Inbal' was said not to be updating activities like her predecessor did, not updating 'specials' and not expelling 'Mikmak' players who swore. One girl even complained that the discontented 'Mikmaks' were being two faced: 'All the 'Mikmaks' were disappointed but still cheered when Inbal arrived.'

\section{The online game}

Besides meeting up to play the computer game, the children played it online when apart so that it constituted a neighbourhood playground. As we said, the children did not meet up much in the afternoons because of the distance between their homes and the need to coordinate rides with their parents. The large number of sites on the computer game enabled the children to fix their 'own places' on the site as a substitute for offline meetings. Sometimes they did this incidentally at the end of an encounter or telephone conversation with a friend, saying something like 'Meet me at the Coconut Gate at 8.30.' Sometimes such invitations involved a ritual as with one of the girls who dared to invite a boy she liked to meet her on the 'Mikmak' game:

You send a note at school - not during class. I wrote it on a piece of paper and tore it a bit so it wouldn't be a proper piece and gave it to him, I wrote a time, a place.

Other children told us that there were different types of meeting places sometimes a popular, busy area where they might meet stranger 'Mikmaks' or else they might keep a secret corner for themselves in the site to chat quietly far from the eyes of other 'Mikmaks' and the from site moderator watching them and what they said. Thus Manor said: If we wanted privacy we'd go to a swap room but not to swap anything just so they wouldn't read what we wanted to say. Other cases revealed that you could root around for familiar friends without 
prearrangement; sooner or later participants learned their friends' 'Mikmak' names and could spot them when they met them by chance on the 'Mikmak' site. Sometimes, if there were no new friends there, children would have incidental conversations with 'Mikmaks' they did not know at all. Such conversations would be short and abrupt partly because of the children's suspicion of strangers: Shelly: 'I don't want to meet them in real life because I read in a book about a man who met a girl in a chat room.'

Playing the offline computer game together also engendered cooperation among a group of children with the aim of accumulating more 'Mikmak' money and 'specials.' These children exchanged passwords and would each enter their friend's 'Mikmak' from home and conduct 'swaps' for them or make 'Mikmak' money or win 'achievements.' If the shared game activity constitutes an undermining of the platform's individualistic message, the exchange of passwords was a gross breaking of the privacy regulations set by the site's operators. The aims behind such cooperation were several and various: 'to beat the machine;' to overcome limitations of time (such as the amount of time a child was allowed to play); or to exploit jointly the individual talents of each partner (such as spotting opportunities for swaps with other children). At the same time, one should bear in mind that besides this solidarity involving symmetrical relations conferring power, some players were more able to influence what went on than others (Tannen, 2005). Indeed, the children reported that joint games on and offline not only brought them together but also were the source of arguments, since the site proscribes more than one child playing with the same 'Mikmak' at the same time. Moreover, the children told us about how hard it is to stand up to peer pressure encouraging them to share passwords. They were afraid that such cooperation would lead to their 'Mikmak' being decorated in a way they didn't like or that an unwanted partner would strip their 'Mikmak' of its assets. Thus online cooperation constituted an object lesson in the pains and rewards of social existence.

It was clear to us that the meanings the children conferred on the game undermined its embedded messages in two aspects:

Social play: the platform encourages individual play. The communitas offered by the operators is intended in the main to bind the children to them and not to each other. It positions the children as individual subjects or objects but the children view the game as social, even if this goes against the logic of the 
platform or its directions. This may be explained by the strong emphasis on collectivism to which the children are exposed by other socialising agents, principally their schools (Katriel, 1999). As we said, the children grow up in a world in which class or group solidarity is viewed as the highest goal. In school they learn about heroes who gave their lives for the common good and they prepare themselves for future participation in a society in which everyone, at all times, is called upon to realise the project of national identity. Behaviour with regard to the computer game which is for the children the most important element of the platform, corresponds with that during more traditional children's games. Volunteering to instruct others, to trade and at times to break the rules, evokes the 'treating' game (Katriel, 1999). Both involve a willingness to help without immediate returns on both an individual and a communal level, with the understanding that your opposite number will pay you back in kind at some point in the future. Swaps on the website are an inbuilt activity. A request, which may be a sentence generated by the computer, is sent by 'Mikmak' to another child. If the request meets with a favourable response, both children enter the 'swaps room' and lay out the items they wish to swap. The system carries out the swap directly, without any further interaction between the children. In fact swapping which appears to take place quickly and to be a means to an end on the site, turns out to be what Katriel (1999) describes as complex cooperation between children accompanying a bustling offline social existence. Thus one may say that the swaps game on the 'Mikmak' platform closely resemble traditional games played by Jewish Israeli children.

A place of their own: The 'Mikmak' platform is presented as enabling absolute control by parents or other responsible adults over the children's play. We discussed above how traditional Israeli children's games are linked with the existence of independent space which Tamar Katriel (1999: 37) calls "on the way home". There, children can experiment with activities outside the two main sites of social supervision: school and home. In this liminal space, children translate social values into their games. The children we spoke with clearly made every effort to carve out a similarly independent space for themselves using the computer game. Long hours in a school, afterschool or clubs framework and the distance between their homes negate the term 'on the way home' but the desire for such a space remains. 


\section{Discussion}

'Mikmak' is an Israeli trans-media platform aimed at children and this study explored it with three aims in mind. First, we were interested the platform's role in exemplifying a cultural context. Second, we wished to discuss the importance of shared analysis of its content for its reception among real audiences and third, to discuss the combined significance of these for childhood socialisation.

\section{Cultural context}

We analyse the implications for childhood of this successful Israeli platform which although culturally 'odorless' (Iwabuchi, 2002), nevertheless reflects a currently dominant Israeli narrative: the rise of consumer individualism through an increasingly Americanised Israeli culture (Almog, 2004; First and Avraham, 2009). Some modes of playing on the platform, although opposing the world order it purports to create, do not take place outside of culture. Although the children at times attempt to undermine the platform, this too is rooted in the cultural order in which they are growing up, including values absorbed from home, school or their neighbourhood (Lee, 2001). The subversive and creative potential of the platform is therefore not of itself, but rather a product of the culture and narrative limits within which the children grow up.

\section{Content and its reception}

Discussion of the social significance of trans-medial platforms usually focuses on the reciprocal relations between their constituent parts as is usual in textual scholarship (Newman, 2012). Such work depends on assumptions regarding the text's 'implied audience' (Iser, 1972). If one believes that the text in question is open, then there is a need to fill the gaps between the various spaces (Jenkins, 2006), while those who believe that it is a narratively and ideologically 'closed' text (Marshall, 2004) assume mutuality and complementarity upheld by the constituent parts of the platform content.

Our analysis tends towards those who view platforms like 'Mikmak' as a closed text. 'Mikmak's creators do not at all wish it to be otherwise, but this does not prevent the children from playing on it differently in the context of their interpretative community (Fish, 1980). This community has universal characteristics typical of childhood and childhood games, but at the same time 
also conforms to local culture. As we pointed out, the children's alternative interpretation is expressed in their lending different weight to the various parts of the platform. Their main focus of interest is in the social aspects of 'Mikmak': playing the computer game together and visiting the play venue with friends, while the feature film, book and television series play a more minor role. Despite this, textual analysis of the entire platform remains relevant. Some of the messages reverberating from the platform (to earn money, to achieve) are included in the children's games so that a joint analysis of the text and its reception is essential.

\section{The platform as a socialising agent}

Like other scholars mentioned above, we object to the claim that transmedial platforms, alongside other technologies, are more important in shaping children as social animals than cultural or interpretative community variables. As we have seen, the socialisation of children is first and foremost influenced by the social world around them with which they have every day, offline contact and in a broader context, by the world view and values held by parents, teachers and friends (Katriel, 1999; Lee, 2001). Other influences, in any format, will be incorporated into a socialisation process only if they conform to these values.

\section{References}

Aarseth, E. (1997). Cybertext: Perspectives on Ergodic Literature. Maryland: Johns Hopkins University Press.

Almog, O. (2004). Predah mi-srulik: shinui arachim ba-elitah ha-yisre'elit [Farewell to Srulik: Changing Values among the Israeli Elite]. Haifa: University of Haifa Press \& Zmora-Bitan.

Alper, M. \& Herr-Stephenson, R. (2013). Transmedia Play: Literacy across Media. The Journal of Media Literacy Education, 5(2), 366-369. 
Apperley, T. (2007). Citizenship and Consumption: Convergence Culture, Transmedia narratives and the Digital Divide. Proceedings of the 4th Australasian Conference on Interactive Entertainment. RMIT University.

Beardsworth, A. \& Bryman, A. (1999). Late Modernity and the Dynamics of Quasification: The Case of the Themed Restaurant. The Sociological Review, 47(2), 228-257.

Billig, M. (1995). Banal Nationalism. London: Sage.

Booth, W. C. (1983). The Rhetoric of Fiction. Chicago: University of Chicago Press.

Bryman, A. (1999). The Disneyization of Society. The Sociological Review, 47(1), 25-47.

Canclini, G. (2001). Consumers and Citizens: Globalization and Multicultural Conflicts. Minneapolis: Minnesota University Press.

Eco, U. (1989). The Open Work. Cambridge, MA: Harvard University Press.

First, A. \& Avraham, E. (2009). America in Jerusalem: Globalization, National Identity, and Israeli advertising. Lanham, Maryland: Lexington Books. \

Fish, S. (1980). Is There a Text in this Class? The Authority of Interpretive Communities. Cambridge, MA: Harvard University Press.

Fiske, J. (1996). Postmodernism and Television. In Curran J. \& Gurevitch, M. (eds.), Mass Media and Society. London: Arnold, pp. 55-67.

Foucault, M. (1971). L'ordre du discours. Paris: Gallimard.

Geertz, C. (1976). From the Native's Point of View. In Basso, K. H. \& Selby, H. A. (eds.), Meaning in Anthropology. Albuquerque: University of New Mexico Press, pp. 221-237.

Hamilton, K. \& Harlow, J. (1995). Retailers Fly in to Exploit Airport Shopping Boom. Sunday Times, 14/5, p. 2.

Hutcheon, L. (2006). A Theory of Adaptation. New York: Routledge.

Iser, W. (1972). The Reading Process: A Phenomenological Approach. New Literary History, 3(2), 279-299.

Iwabuchi, K. (2002). Recentering Globalization: Popular Culture and Japanese Transnationalism. Durham, NC: Duke University Press. 
Jenkins, H. (2006). Convergence Culture: Where Old and New Media Collide. New York: New York University Press.

Katriel, T. (1999). Milot mafte'ah: dfusei tarbut vetikshoret beisrael [Patterns of Culture and Communication in Israel]. Haifa: University of Haifa Press \& Zmora-Bitan.

Katz, E. \& Hass, H. (2000). Leisure Culture in Israel. Tel Aviv: Open University Press.

Kinder, M. (1991). Playing with Power in Movies, Television, and Video Games: From Muppet Babies to Teenage Mutant Ninja Turtles. Berkeley: University of California Press.

King, N. (1992). The Impact of Context on the Play of Young Children. In Kessler, S. \& Swadener, B. (eds.), Reconceptualizing the Early Childhood Curriculum: Beginning the Dialogue. New York: Teachers Collage Press, pp. 43-61.

Lee, N. (2001). Childhood and Society: Growing up in An Age of Uncertainty. Buckingham: Open University Press.

Malinowski, B. (1923). The Problem of Meaning in Primitive languages. In Ogden C. K. and Richards I. A., The meaning of meaning: A study of the influence of language upon thought and of the science of symbolism. Cambridge: Cambridge University Press, pp. 1-84.

Marshall, P. D. (2004). New Media Cultures. London: Arnold.

Mayseless, O. \& Salomon, G. (2003). Dialectic Contradictions in the Experience of Israeli Jewish Adolescents. In Pajares, F. \& Urdan, T. (eds.), International perspectives on adolescence, Greenwich, CT: Information, pp. 149-171.

Muniz Jr, A. M. \& O’Guinn, T. C. (2001). Brand Community. Journal of Consumer Research, 27(4), 412-432.

Newman, M. (2012). Intermediality and Transmedia Storytelling The Center for 21st Century Studies. Accessed 16.09.2013. URL: http://www.c21 uwm. com/2012/09/17/intermediality-and-transmedia-storytelling/.

Op'tLand, R. (2009). Another Endless November: AOL, WoW, and the Corporatization of a Niche Market. Journal of Virtual Worlds Research, 2(3). Accessed 16.09.2013. URL: http://journals.tdl.org/jvwr/article/viewArticle/660/. 
Postman, N. (1983). The Disappearing Child. Educational Leadership, 40(6), $10-17$.

Radway, J. (1984). Interpretive Communities and Variable Literacies: The Functions of Romance Reading. Daedalus, 113(3), 49-73.

Ryan, M. (2008). Transfictionality across Media. In Pier, J. \& Ángel García Landa, J. (eds.), Theorizing Narrativity. Berlin: Walter de Gruyter, pp. 385-418.

Seiter, E. (1993). Sold Separately: Parents and Children in Consumer Culture. New Brunswick, NJ: Rutgers University Press.

Shaw, C, Brady, L. M. \& Davey, C. (2011). Guidelines for Research with Children and Young People. London: National Children's Bureau Research Centre.

Shemer, N. (December, 2011). Schalit most-Googled term in Israel 2011 Accesses 01.11.2013. URL: http://www.jpost.com/LandedPages/PrintArticle. aspx?id=249461.

Tannen, D. (2005). Conversational Style: Analyzing Talk among Friends. Oxford: Oxford University Press.

Weisblei, E. (2011). Data on the participation of youth recreational activities. Accessed 29.09.2013. URL: http://www.knesset.gov.il/mmm/data/pdf/ m02965.pdf.

Wheeler, W. (1962). Frontiers, Americanization and Romantic Pluralism. Midcontinent American Studies Journal, 3(2), 27-41.

Yee, N. (2006). Motivations for Play in Online Games. Cyberpsychology \& Behavior, 9(6), 772-775.

Ynet (September, 2013). 33\% of the Chidren in Israel Spend the Afternoon in front of a Screen. Accessed 29.09.2013. URL: http://www.ynet.co.il/ articles/0,7340,L-4428504,00.html. 